\title{
Capacidade Competitiva do Jatobá com Adubos Verdes, Forrageiras e Plantas Daninhas ${ }^{1}$
}

\author{
Competitive Capacity of Hymenaea courbaril with Green Manure, Forage Species and Weeds
}

\author{
GANDINI, A.M.M..$^{2}$, SANTOS, J.B. ${ }^{3}$, ANDREZZA, M.M.G. ${ }^{2}$, SANTANA, R.C. ${ }^{4}$, CUNHA, V.C. ${ }^{5}$, \\ VALADÃO SILVA, D. ${ }^{6}$ e FIORE, R.A. ${ }^{7}$
}

\begin{abstract}
RESUMO - O estudo do consórcio entre espécies anuais e perenes representa uma ferramenta importante no processo de implantação e manejo florestal. O objetivo deste trabalho foi avaliar a capacidade competitiva do jatobá (Hymenaea courbaril) com espécies de adubos verdes, forrageiras e plantas daninhas quanto à alocação de matéria seca, área foliar e concentração de nutrientes. Foram conduzidos dois experimentos, sendo os tratamentos compostos pela combinação de mudas de jatobá, desenvolvendo-se isoladamente ou em competição com cada uma das seguintes espécies: Brachiaria humidicola, Brachiaria brizantha, Brachiaria decumbens, Panicum maximum, Cajanus cajan, Canavalia ensiformis e Mucuna aterrima (experimento 1) e Bidens pilosa, Cenchrus echinatus, Euphorbia heterophylla, Lolium multiflorum e Solanum americanum (experimento 2), mais o cultivo de cada planta daninha e consorte isolada. Após convivência por 60 dias, as plantas foram coletadas para avaliação de matéria seca, área foliar e teor de nutrientes. Observou-se que a competição entre as plantas não promoveu alterações na produção de matéria seca ou área foliar do jatobá. Tendo em vista o exposto, verifica-se que a capacidade competitiva do jatobá não é afetada pela presença das espécies de adubos verdes e forrageiras, possibilitando convivência em fase inicial de desenvolvimento. Quanto à convivência das plantas daninhas com o jatobá, observou-se efeito positivo no acúmulo de nutrientes por estas.
\end{abstract}

Palavras-chave: Hymenaea courbaril, competição, consorciação, macronutrientes.

\begin{abstract}
The study of intercropping between annual and perennial plants is an important tool in the process of forest implantation and management. The objective of this study was to assess the competitive capacity of jatoba (Hymeneae courbaril) against green manure, forage and weed species, regarding the allocation of dry matter, leaf area and nutritional content. Two experiments were installed and the treatments consisted of combinations of jatoba seedlings per plot, alone or under competition with each one of the following plant species: Brachiaria humidicola, Brachiaria brizantha, Brachiaria decumbens, Panicum maximum, Cajanus cajan, Canavalia ensiformis and Mucuna aterrima (experiment 1) and Bidens pilosa, Cenchrus echinatus, Euphorbia heterophylla, Lolium multiflorum and Solanum americanum (experiment 2), plus the cultivation of each weed or counterpart alone. After 60 days of intercropping, the plants were collected to assess dry matter, leaf area and nutrient accumulation. Competition between the plant species did not promote any changes in jatoba dry matter production and leaf area of jatoba. Thus, the competitive capacity of jatoba is not affected by the green manure and forage species, at its early phases of development. A positive effect on nutrient accumulation by the weeds was observed when they were grown in the presence of jatoba.
\end{abstract}

Keywords: Hymenaea courbaril, competition, intercropping, macronutrients.

\footnotetext{
1 Recebido para publicação em 21.1.2011 e aprovado em 3.6.2011.

2 Engenheria Florestal, Mestre em Produção Vegetal, Universidade Federal dos Vales do Jequinhonha e Mucuri - UFVJM, Faculdade de Ciências Agrárias, Campus II - Rodovia MGT 367 - km 583, nº 5000, Bairro Alto da Jacuba, 39100-000 Diamantina-MG, <elizzandragandini@yahoo.com.br>, <andrezzagandini@yahoo.com.br>; ${ }^{3}$ Professor Adjunto, Dep. de Agronomia, UFVJM, <barbosa@pq.cnpq.br>; ${ }^{4}$ Professor Adjunto, Dep. de Engenharia Florestal, UFVJM, <silviculturaufvjm@yahoo.com.br>;

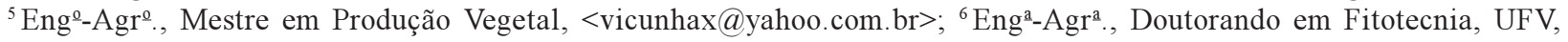
$<$ danielvaladaos@yahoo.com.br>; ${ }^{6}$ Engenheira Florestal, Mestranda do Programa de Pós-Graduação em Ciência Florestal, UFVJM.
} 


\section{INTRODUÇÃO}

O jatobá (Hymenaea courbarit) é uma árvore da família Fabacea, muito utilizada para fins madeireiros e não madeireiros, como móveis, construção civil, recuperação de áreas degradadas, frutos comestiveis, produtos fitoquímicos e medicinais (Lorenzi, 2002; Carvalho Filho et al., 2003; Gorchov et al., 2004).

Algumas espécies florestais possuem alta sensibilidade à competição por água, luz e nutrientes quando cultivadas sem o controle das plantas daninhas, particularmente com espécies de rápido crescimento, como as gramineas (Silva et al., 2000). Com esse efeito, a ausência de controle ou manejo inadequado dessas invasoras, nos estádios iniciais da implantação florestal, pode implicar elevadas perdas de produtividade. Para o jatobá, são praticamente inexistentes na literatura trabalhos que avaliam o seu desempenho em sistema de consórcio.

O estudo de propostas para o consorciamento de espécies florestais e forrageiras ou adubos verdes se faz necessário em função de estabelecer os critérios de competição e as melhores espécies consortes. Pesquisas que avaliam o desenvolvimento conjunto entre as espécies mencionadas também possibilitam conhecer a demanda dos nutrientes disponiveis no solo pelas plantas consortes e o grau de competição destas, evitando que a competição torne-se nociva às espécies.

Atualmente, muitos esforços são empregados na tentativa de diminuição dos custos de implantação de uma floresta. A consorciação, a propósito, poderá reduzir os referidos custos, pois deve-se considerar a retirada de produtos e subprodutos florestais diversificados obtidos em épocas ou anos diferentes, o que irá garantir uma receita escalonada - garantia de subsistência de pequenos e médios proprietários rurais (Pes et al., 1995).

O entendimento da interferência promovida pelas plantas daninhas sobre as culturas florestais se faz necessário em virtude do potencial agressivo daquelas sobre estas, principalmente na competição por água e nutrientes. Em áreas de reflorestamento, a presença de plantas daninhas torna-se indesejável tanto do ponto de vista silvicultural quanto econômico. Desse modo, é necessário o monitoramento periódico e realizar intervenções para reduzir a infestação, o que acarreta aumento considerável do custo de implantação. Por outro lado, do ponto de vista ecológico, a presença de várias espécies em algumas áreas pode ser desejável, uma vez que ela favorece a biodiversidade, promove maior cobertura do solo, reduz a erosão, melhora a estruturação e contribui com o aporte de matéria orgânica do solo (Davide \& Botelho, 1999; Davide et al., 2000).

O objetivo deste estudo foi avaliar a capacidade competitiva do jatobá com espécies de adubos verdes, forrageiras e plantas daninhas quanto à alocação de matéria seca, área foliar e concentração de nutrientes.

\section{MATERIAL E MÉTODOS}

Foram realizados dois experimentos em casa de vegetação (cobertura de polietileno transparente e laterais protegidas com sombrite $50 \%$ ), no municipio de Diamantina-MG. O clima local é classificado como Cwb (Köppen), temperado úmido, com inverno seco e chuvas no verão, com precipitação média anual de $1.405 \mathrm{~mm}$, altitude média de $1.296 \mathrm{~m}$ e temperatura média de $18,1^{\circ} \mathrm{C}$. O substrato utilizado para condução dos experimentos foi Latossolo Vermelho-Amarelo de textura média, devidamente corrigido, apresentando $\mathrm{pH}$ em água de 4,7 e os respectivos valores para: $\mathrm{Ca}, \mathrm{Mg}$ e $\mathrm{Al}-$ 0,7, 0,4 e 0,7 $\mathrm{cmol}_{\mathrm{c}} \mathrm{dm}^{-3}$; e P (Mehlich ${ }^{1}$ ) e K-0,1 e $6 \mathrm{mg} \mathrm{dm}^{-3}$, antes da condução do experimento.

As mudas de jatobá (Hymenaea courbarit) utilizadas nos experimentos foram produzidas a partir de sementes coletadas de progênies provenientes do município de Curvelo-MG e de Mendanha, município de Couto Magalhães de Minas-MG. Para quebra da dormência, as sementes foram escarificadas com uso de esmeril e, em seguida, imersas em água por 24 horas (adaptação de Fowler \& Bianchetti, 2000). Após esses procedimentos, realizou-se a semeadura em tubetes de polipropileno contendo substrato à base de $40 \%$ de vermiculita, $30 \%$ de casca de arroz carbonizada e $30 \%$ de fibra de coco. Ao substrato foram adicionados 7,0 $\mathrm{g} \mathrm{dm}^{-3}$ de Osmocote ${ }^{\circledR}$ (NPK 15:09:12 + 1\% de $\mathrm{Mg} ; 2,3 \%$ de $\mathrm{S} ; 0,02 \%$ de $\mathrm{B} ; 0,05 \%$ de $\mathrm{Cu}$; $1 \%$ de $\mathrm{Fe} ; 0,06 \%$ de $\mathrm{Mn} ; 0,02 \%$ de $\mathrm{Mo}$; e $0,05 \%$ 
de $\mathrm{Zn}$ ), fertilizante de liberação estimada para quatro a seis meses.

O delineamento adotado nos experimentos foi o de blocos ao acaso, sendo cada vaso uma parcela experimental.

O primeiro experimento foi conduzido de junho a agosto de 2009. Os tratamentos, em número de 15, foram compostos pela combinação de mudas de jatobá em desenvolvimento isolado ou em competição com cada uma das seguintes espécies: Brachiaria humidicola (braquiária), Brachiaria brizantha (braquiarão), Brachiaria decumbens (braquiária), Panicum maximum (tanzânia), Cajanus cajan (feijãoguandu), Canavalia ensiformis (feijão-de-porco) e Mucuna aterrima (mucuna-preta), mais o cultivo isolado de cada uma destas espécies consortes. Cada tratamento contou com quatro repetições, totalizando 60 vasos.

As mudas de jatobá, com 130 dias de idade, foram transplantadas para vasos com capacidade para $6 \mathrm{dm}^{3}$, preenchidos com amostra de Latossolo Vermelho-Amarelo de textura média. Aos 21 dias após o transplantio das mudas, procedeu-se à semeadura de 30 sementes de cada uma das espécies consortes. Após emergência, foi realizado o desbaste, deixando-se uma planta por vaso. Passados 60 dias de convivência, todas as plantas foram coletadas, sendo cortadas rente ao solo para determinação da matéria seca da parte aérea (MSPA). Realizou-se a imersão do conjunto substrato e sistema de raízes em baldes cheios de água, visando facilitar a separação e quantificação das raízes (MSR). Para isso, as plantas foram secas em estufa de circulação forçada por 72 horas a $65^{\circ} \mathrm{C}$. Posteriormente, foram pesadas em balança de precisão $(0,0001 \mathrm{~g})$. Em seguida, as folhas foram moídas em moinho tipo Wiley e depois submetidas à análise química, para determinação das concentrações de nutrientes. Para determinação dos teores de $\mathrm{P}$ e $\mathrm{K}$, foi efetuada a digestão nítrico-perclórica, obtendo-se extratos para determinação dos teores de $\mathrm{P}$, por colorimetria, e de $\mathrm{K}$, por fotometria de chama. $\mathrm{O} \mathrm{N}$ total foi determinado pelo método Kjeldhal, após digestão sulfúrica (Malavolta et al., 1997).

O segundo experimento foi avaliado entre os meses de outubro e dezembro de 2009. Mudas de jatobá, produzidas conforme descrito no primeiro experimento, foram transplantadas para vasos com capacidade para $6 \mathrm{dm}^{3}$, preenchidos com o mesmo tipo de solo mencionado no experimento 1 . Após 21 dias de transplantio das mudas, realizou-se a semeadura das seguintes espécies de plantas daninhas: Bidens pilosa (picão-preto), Cenchrus echinatus (capim-carrapicho), Euphorbia heterophylla (leiteiro), Lolium multiflorum (azevém) e Solanum americanum (maria-pretinha). Os tratamentos, em número de 11 , foram resultantes da combinação de mudas de jatobá em competição com cada uma das cinco espécies daninhas mais o cultivo de cada planta daninha isolada e do jatobá, com quatro repetições. Em cada vaso foram semeadas 30 sementes da planta daninha, conforme o tratamento, sendo, após emergência, realizado o desbaste, deixando-se uma planta por vaso. Decorridos 60 dias da convivência, todas as plantas foram coletadas. Quanto ao jatobá, foram destacadas as folhas para determinação da área foliar, sendo estas escaneadas e digitalizadas para o software Determinador Digital de Áreas (DAA) (Ferreira et al., 2008).

A área foliar específica (AFE) foi calculada a partir da razão entre área foliar (AF) e matéria seca das folhas de cada muda. Para o cálculo da razão de área foliar ( $R A F)$, procedeu se à divisão da área foliar (AF) pela matéria seca total (MST). Para determinação da MSPA e MSR e quantificação de $\mathrm{N}, \mathrm{P}$ e K, procedeu-se como relatado para o primeiro experimento.

Em ambos os experimentos, os dados foram submetidos aos testes das pressuposições do modelo matemático (normalidade e homogeneidade das variâncias) e, em seguida, à análise de variância; as médias, quando significativas, foram comparadas entre si a $5 \%$ pelo teste F ou teste de Tukey.

\section{RESULTADOS E DISCUSSÃO}

No primeiro experimento, a produção de matéria seca das mudas de jatobá não diferiu entre os modos de cultivo solteiro e consorciado, sendo os valores médios encontrados de $5,08 \mathrm{~g}$ por planta para MSPA, $11,13 \mathrm{~g}$ por planta para MSR e RPAR de 0,52.

Os resultados se assemelham aos encontrados por Duboc et al. (1996), que obtiveram valores de 5,84 g por planta de MSPA e 0,60 de 
RPAR em mudas de jatobá. Bocchese et al. (2007) observaram que mudas das espécies arbóreas Dyperix alata (cumbaru), Astronium concinnum (gonçalo-alves), Hymenaea stgonocarpa (jatobá-do-cerrado) e Eucalyptus citriodora (eucalipto), cultivadas em competição com Brachiaria brizantha cv. Marandu, também não diferiram na produção de matéria seca da parte aérea (MSPA) e da raiz (MSR).

A MSPA das plantas consortes cultivadas juntamente com mudas de jatobá foi afetada apenas para a forrageira $B$. decumbens em plantio consorciado, com aumento da alocação na parte aérea (Tabela 1). Campos et al. (2007) afirmam que essa forrageira, quando cultivada sombreada, apresenta aumento na taxa de alongamento foliar, resultando em maior área foliar para captação de luz em ambiente de reduzida luminosidade. Para a variável MSR, a maior produção foi obtida no plantio isolado, possivelmente devido à maior área livre para o desenvolvimento do sistema radicular (Tabela 1).

Assim, o uso das demais espécies junto com o jatobá em sistemas agroflorestais pode ser uma alternativa viável.

Entre as plantas consortes, verificou-se considerável diferença nas variáveis avaliadas. As espécies que mais se destacaram foram: $B$. decumbens, com maior produção de MSPA no cultivo em competição, e B. humidicola, no cultivo isolado; para a variável MSR, C. ensiformis obteve valores superiores aos das demais espécies nos dois modos de cultivo; já para a RPAR, as espécies mais relevantes foram $B$. humidicola e $P$. maximum, respectivamente nos cultivos em competição e isolado (Tabela 1).

O comportamento observado entre jatobá e forrageiras indica que estudos sobre o consórcio com o gênero Brachiaria podem ser realizados em áreas de pastagens, sem que haja interferências significativas no crescimento inicial das mudas de jatobá e da planta forrageira.

$\mathrm{O}$ teor de nutrientes nos tecidos foliares das mudas de jatobá em competição com as espécies forrageiras e adubos verdes não diferiu. Os teores médios encontrados para os nutrientes estudados foram de 16,06, 2,21 e $30,06 \mathrm{~g} \mathrm{~kg}^{-1}$, respectivamente para nitrogênio, fósforo e potássio.

Quanto ao teor de nitrogênio nos tecidos foliares das plantas forrageiras e dos adubos verdes (Tabela 2), observou-se maior acúmulo para as plantas cultivadas isoladamente. Maiores reduções foram observadas nas forrageiras $B$. brizantha e $B$. decumbens, para as quais a convivência com o jatobá promoveu restrição na concentração do referido nutriente nas proporções de 100 e $82 \%$, respectivamente. Quando cultivadas em consórcio, as forrageiras tiveram menor área livre para desenvolvimento do sistema radicular e, consequentemente, menor superficie para absorção de nitrogênio e potássio.

Tabela 1 - Produção de matéria seca da parte aérea (MSPA) e da raiz (MSR) e relação parte aérea-raiz (RPAR) de plantas forrageiras e adubos verdes em plantios isolados ou em competição com mudas de jatobá

\begin{tabular}{|c|c|c|c|c|c|c|}
\hline \multirow{3}{*}{ Tratamento } & \multicolumn{2}{|c|}{ MSPA } & \multicolumn{2}{|c|}{ MSR } & \multicolumn{2}{|c|}{ RPAR } \\
\hline & \multicolumn{6}{|c|}{ (g) } \\
\hline & Competição & Isolado & Competição & Isolado & Competição & Isolado \\
\hline Brachiaria humidicola & $8,17 \mathrm{Aab}$ & 7,92 Aa & $3,54 \mathrm{Ab}$ & $4,07 \mathrm{Abc}$ & $2,32 \mathrm{Aa}$ & 1,92 Aab \\
\hline Brachiaria brizantha & $5,14 \mathrm{Abc}$ & $3,17 \mathrm{Aabc}$ & $2,58 \mathrm{Ab}$ & $2,69 \mathrm{Ac}$ & $1,99 \mathrm{Aab}$ & $1,23 \mathrm{Aabc}$ \\
\hline Brachiaria decumbens & $10,94 \mathrm{Aa}$ & 4,46 Babc & $3,81 \mathrm{Bb}$ & $5,25 \mathrm{Ab}$ & $2,88 \mathrm{Aa}$ & $0,89 \mathrm{Bbc}$ \\
\hline Panicum maximum & $5,92 \mathrm{Abc}$ & 6,69 Aab & $3,04 \mathrm{Ab}$ & $3,15 \mathrm{Abc}$ & $1,95 \mathrm{Aab}$ & $2,13 \mathrm{Aa}$ \\
\hline Cajanus cajan & $1,11 \mathrm{Acd}$ & $3,06 \mathrm{Abc}$ & $2,43 \mathrm{Abc}$ & $2,84 \mathrm{Ac}$ & $0,39 \mathrm{Ac}$ & $1,12 \mathrm{Aabc}$ \\
\hline Canavalia ensiformis & $3,38 \mathrm{Abcd}$ & $2,80 \mathrm{Abc}$ & $8,85 \mathrm{Aa}$ & $10,09 \mathrm{Aa}$ & $0,38 \mathrm{Ac}$ & $0,28 \mathrm{Ac}$ \\
\hline Mucuna aterrima & 2,58 Acd & 3,82 Aabc & $3,27 \mathrm{Ab}$ & $4,19 \mathrm{Abc}$ & $0,78 \mathrm{Abc}$ & $0,93 \mathrm{Aabc}$ \\
\hline $\mathrm{CV}(\%)$ & \multicolumn{2}{|c|}{49,39} & \multicolumn{2}{|c|}{25,23} & \multicolumn{2}{|c|}{41,01} \\
\hline
\end{tabular}

Médias seguidas por letras iguais maiúsculas na linha não diferem a 5\% pelo teste $\mathrm{F}$; e as seguidas por letras minúsculas na coluna, para cada variável, não diferem entre si a $5 \%$ pelo teste de Tukey. 
Tabela 2 - Acúmulo de nitrogênio (N), fósforo (P) e potássio (K) nas folhas de plantas forrageiras e leguminosas em cultivo solteiro ou em competição com mudas de jatobá

\begin{tabular}{|c|c|c|c|c|c|c|}
\hline \multirow{3}{*}{ Tratamento } & \multicolumn{2}{|c|}{ Nitrogênio } & \multicolumn{2}{|c|}{ Fósforo } & \multicolumn{2}{|c|}{ Potássio } \\
\hline & \multicolumn{6}{|c|}{$\left(\mathrm{g} \mathrm{kg}^{-1}\right)$} \\
\hline & Competição & Isolado & Competição & Isolado & Competição & Isolado \\
\hline Brachiaria humidicola & 9,60 Acd & $13,92 \mathrm{Ab}$ & $2,24 \mathrm{Bd}$ & $11,49 \mathrm{Abc}$ & $32,35 \mathrm{Abc}$ & $13,28 \mathrm{Ba}$ \\
\hline Brachiaria brizantha & $10,53 \mathrm{Bcd}$ & $21,02 \mathrm{Ab}$ & $16,81 \mathrm{Aa}$ & $19,54 \mathrm{Aa}$ & 35,46 Aabc & $19,16 \mathrm{Ba}$ \\
\hline Brachiaria decumbens & $9,22 \mathrm{Bd}$ & $16,78 \mathrm{Ab}$ & $3,97 \mathrm{Bcd}$ & $14,06 \mathrm{Aabc}$ & $43,58 \mathrm{Abc}$ & $17,13 \mathrm{Ba}$ \\
\hline Panicum maximum & 10,13 Acd & $14,40 \mathrm{Ab}$ & $13,65 \mathrm{Aab}$ & $17,43 \mathrm{Aab}$ & $50,48 \mathrm{Aa}$ & $13,17 \mathrm{Ba}$ \\
\hline Cajanus cajan & $26,28 \mathrm{Aa}$ & $28,82 \mathrm{Aa}$ & 8,64 Abcd & 9,36 Acd & $28,73 \mathrm{Abc}$ & $17,84 \mathrm{Ba}$ \\
\hline Canavalia ensiformis & $18,82 \mathrm{Ab}$ & $19,17 \mathrm{Ab}$ & 4,49 Acd & $3,31 \mathrm{Ad}$ & $25,03 \mathrm{Ac}$ & $15,22 \mathrm{Aa}$ \\
\hline Mucuna aterrima & $16,60 \mathrm{Abc}$ & $15,65 \mathrm{Ab}$ & 9,40 Abc & $11,91 \mathrm{Abc}$ & $31,11 \mathrm{Abc}$ & $20,00 \mathrm{Ba}$ \\
\hline $\mathrm{CV}(\%)$ & \multicolumn{2}{|c|}{19,96} & \multicolumn{2}{|c|}{30,03} & \multicolumn{2}{|c|}{28,72} \\
\hline
\end{tabular}

Médias seguidas por letras iguais maiúsculas na linha não diferem a 5\% pelo teste $\mathrm{F}$; e as seguidas por letras minúsculas na coluna, para cada variável, não diferem entre si a $5 \%$ pelo teste de Tukey.

Entre as plantas forrageiras e adubos verdes, verificaram-se consideráveis diferenças no acúmulo de nitrogênio no cultivo consorciado. Quando cultivadas isoladamente, apenas C. cajan diferiu das demais espécies. Para o fósforo, verificou-se também maior acúmulo nas plantas cultivadas isoladas, mas somente $B$. humidicola e $B$. decumbens diferiram estatisticamente, tendo apresentado acúmulo 413 e $254 \%$, respectivamente, superior ao do cultivo consorciado. Constata-se que as espécies diferiram muito quanto ao acúmulo de fósforo: valores discrepantes são observados tanto entre as forrageiras quanto entre os adubos verdes.

$\mathrm{Na}$ avaliação do potencial competitivo do jatobá sobre as forrageiras e adubos verdes, quanto ao teor do potássio, verificou-se que a convivência promoveu efeito positivo sobre o aumento da concentração desse nutriente. Ainda para o potássio, $P$. maximum destacouse, apresentando $283 \%$ a mais quando se desenvolveu em plantio consorciado. O maior acúmulo desse nutriente nas plantas cultivadas em consórcio com o jatobá, provavelmente, se deve à presença da vermiculita $(40 \%)$ no substrato de produção das mudas, visto que ela é uma das formas minerais do potássio no solo (Prado, 2008). Verifica-se, portanto, que não só a gramínea, mas a grande maioria das plantas estudadas (Tabela 2), foi capaz de utilizar o potássio disponível para as mudas de jatobá. De acordo com Duboc et al. (1996), o jatobá tem baixo requerimento de potássio.
Andrade et al. (2002) verificaram comportamento semelhante ao obtido neste estudo para as gramineas $B$. brizantha e $B$. decumbens, que, quando cultivadas em consórcio com a espécie arbórea Stryphnodendron guianense (Baginha), apresentaram maiores teores de potássio. Silva et al. (2009), em avaliação de $B$. brizantha em competição com soja, constataram que a graminea obteve maior acúmulo de nitrogênio, fósforo e potássio. Quanto ao acúmulo entre plantas, observa-se que para o cultivo consorciado existe diferença: $P$. maximum obteve maior acúmulo, e $C$. ensiformis, menor (Tabela 2).

No segundo experimento, observou-se que, independentemente da espécie competidora, as características avaliadas do jatobá não foram alteradas. A produção e o acúmulo da MSPA e MSR foram semelhantes em ambas as situações (cultivo solteiro e consorciado). Os valores médios encontrados para a produção de MSPA e MSR foram, respectivamente, de 17,95 e 9,22 g por planta. Para área foliar total (AF) e específica (AFE) e razão de área foliar (RAF), as médias observadas foram de $976,22 \mathrm{~cm}^{2}, 97,47$ e $34,69 \mathrm{~cm}^{2} \mathrm{~g}^{-1}$, respectivamente. De acordo com Barbieri Júnior et al. (2007), o desenvolvimento da cultura proporciona aumento de área foliar e matéria seca das folhas, provocando a diminuição da AFE.

Os resultados obtidos - apesar de não corroborarem as informações de Pitelli \& Karam (1988), para os quais espécies daninhas anuais são bastante prejudiciais nas fases 
iniciais de crescimento das florestas - são importantes na determinação do período crítico de convivência. Pesquisa enfatiza que espécies arbustivas e arbóreas podem ser mais competitivas em fase mais adiantada do ciclo da floresta (Dias et al., 2005), supondo que inicialmente o lento crescimento ofereça menor competição pelos recursos do solo, principalmente por nutrientes. É provável que o período de 60 dias tenha sido insuficiente para esgotamento dos nutrientes disponiveis no substrato - contrariamente ao observado para competição entre plantas daninhas e culturas anuais (Bianchi et al., 2006). Por outro lado, reforçase a tese de que em 60 dias de convivência a competição exercida pelas plantas daninhas não é suficiente para comprometer o desenvolvimento de mudas do jatobá.

$\mathrm{Na}$ avaliação do potencial competitivo do jatobá sobre as plantas daninhas, verificou-se que a convivência promoveu efeito positivo sobre o acúmulo de matéria seca para C. echinatus. Na mesma situação, a RPAR foi aumentada para as espécies $B$. pilosa e $E$. heterophylla, ou seja, investiram-se mais recursos na formação de parte aérea quando em competição com o jatobá (Tabela 3). Apesar de a competição não promover efeito sobre o acúmulo de MSPA dessas duas espécies, o sistema radicular foi afetado, apresentando valores inferiores a 50\% em relação aos observados para suas respectivas testemunhas, na ausência de competição. É provável que o sistema radicular dessas duas espécies seja mais sensivel à competição com o jatobá oposto ao comumente observado para competição entre a planta daninha $E$. heterophylla $\mathrm{e}$ culturas anuais, como a soja (Carvalho et al., 2010). Entre as plantas, verifica-se que, para as três variáveis estudadas, somente no cultivo sob competição é que ocorreu diferença estatística, sendo $C$. echinatus a planta que obteve maior produção de MSPA e MSR.

Observa-se que mudas de jatobá sob a interferência da planta daninha $B$. pilosa acumularam $119 \%$ a mais de nitrogênio que a testemunha (Tabela 4). Favero et al. (2000) relatam que plantas infestantes podem promover a ciclagem de nutrientes no solo e que $B$. pilosa destaca-se no acúmulo dos nutrientes fósforo, potássio e magnésio. Segundo Barroso et al. (2005), grandes quantidades de nitrogênio são requeridas pelas plantas, sobretudo na fase inicial de crescimento. Perin et al. (2004) relatam que o nitrogênio é um dos nutrientes que mais limitam o crescimento das plantas nos trópicos.

Tabela 4 - Acúmulo de nitrogênio $(\mathrm{N})$, fósforo $(\mathrm{P})$ e potássio (K) nas folhas das mudas de jatobá em cultivo isolado (testemunha) ou quando em competição com plantas daninhas

\begin{tabular}{|l|c|c|c|}
\hline \multirow{2}{*}{\multicolumn{1}{|c|}{ Cultivo }} & Nitrogênio & Fósforo & Potássio \\
\cline { 2 - 4 } & \multicolumn{3}{|c|}{$\left(\mathrm{g} \mathrm{kg}^{-1}\right)$} \\
\hline Isolado & $20,49 \mathrm{~b}$ & $3,55 \mathrm{a}$ & $28,14 \mathrm{~b}$ \\
\hline Bidens pilosa & $44,93 \mathrm{a}$ & $3,14 \mathrm{a}$ & $31,48 \mathrm{ab}$ \\
\hline Cenchrus echinatus & $12,79 \mathrm{~b}$ & $1,46 \mathrm{a}$ & $28,21 \mathrm{~b}$ \\
\hline Euphorbia heterophylla & $16,73 \mathrm{~b}$ & $1,91 \mathrm{a}$ & $34,14 \mathrm{ab}$ \\
\hline Lolium multiflorum & $11,00 \mathrm{~b}$ & $2,02 \mathrm{a}$ & $33,01 \mathrm{ab}$ \\
\hline Solanum americanum & $15,23 \mathrm{~b}$ & $2,98 \mathrm{a}$ & $38,04 \mathrm{a}$ \\
\hline \multicolumn{1}{|c|}{ CV (\%) } & 32,23 & 47,96 & 10,46 \\
\hline
\end{tabular}

Médias seguidas por letras iguais na coluna, para cada variável, não diferem entre si pelo teste $\mathrm{F}$ a $5 \%$ de probabilidade de erro.

Tabela 3 - Produção de matéria seca da parte da aérea (MSPA), da raiz (MSR) e relação parte aérea e raiz (RPAR) de plantas daninhas em competição ou não com mudas de jatobá

\begin{tabular}{|c|c|c|c|c|c|c|}
\hline \multirow{3}{*}{ Tratamento } & \multicolumn{2}{|c|}{ MSPA } & \multicolumn{2}{|c|}{ MSR } & \multicolumn{2}{|c|}{ RPAR } \\
\hline & \multicolumn{6}{|c|}{ (g) } \\
\hline & Competição & Isolado & Competição & Isolado & Competição & Isolado \\
\hline Cenchrus echinatus & $5,21 \mathrm{Aa}$ & $3,15 \mathrm{Ba}$ & $5,32 \mathrm{Aa}$ & $2,94 \mathrm{Ba}$ & $1,02 \mathrm{Ab}$ & $1,32 \mathrm{Aa}$ \\
\hline Bidens pilosa & $2,10 \mathrm{Ab}$ & $1,91 \mathrm{Aa}$ & $0,68 \mathrm{Ab}$ & $1,41 \mathrm{Aa}$ & $3,08 \mathrm{Ab}$ & $1,37 \mathrm{Ba}$ \\
\hline Euphorbia heterophylla & $1,75 \mathrm{Ab}$ & $1,14 \mathrm{Aa}$ & $0,18 \mathrm{Ab}$ & $0,64 \mathrm{Aa}$ & $9,94 \mathrm{Aa}$ & $2,05 \mathrm{Ba}$ \\
\hline Lolium multiflorum & 3,03 Aab & $1,96 \mathrm{Aa}$ & $3,97 \mathrm{Aa}$ & $3,24 \mathrm{Aa}$ & $0,76 \mathrm{Ab}$ & $0,56 \mathrm{Aa}$ \\
\hline Solanum americanum & $1,26 \mathrm{Ab}$ & $0,81 \mathrm{Aa}$ & $0,80 \mathrm{Ab}$ & $0,74 \mathrm{Aa}$ & $1,64 \mathrm{Ab}$ & $1,19 \mathrm{Aa}$ \\
\hline $\mathrm{CV}(\%)$ & \multicolumn{2}{|c|}{52,26} & \multicolumn{2}{|c|}{64,35} & \multicolumn{2}{|c|}{49,23} \\
\hline
\end{tabular}

Médias seguidas por letras iguais maiúsculas na linha não diferem a $5 \%$ pelo teste $\mathrm{F}$; e as seguidas por letras minúsculas na coluna, para cada variável, não diferem entre si a $5 \%$ pelo teste de Tukey. 
Considerando o lento crescimento do jatobá, é provável que a rápida mobilização do nitrogênio observada em $B$. pilosa possa ser útil também às raízes daquela espécie arbórea. As prováveis inferências para esse fato podem ser explicadas nas relações simbióticas já constatadas para B. pilosa (Cui \& He, 2009).

Verifica-se que as mudas de jatobá cultivadas juntamente com as plantas daninhas, exceto Cenchrus echinatus, acumularam maiores teores de fósforo, destacando-se as mudas cultivadas juntamente com Solanum americanum, com acúmulo cerca de $85 \%$ superior (Tabela 4). Fernandes et al. (2007) relatam que a carência de fósforo constitui-se em um fator limitante para o crescimento das espécies florestais exóticas e nativas. Espécies florestais como pínus e eucalipto sofrem sensivelmente a competição imposta pelas plantas daninhas. Extensos plantios dessas espécies são comprometidos pela deficiência ou atraso na limpeza dos talhões. Características como maior capacidade de extrair água do solo e rotas fotossintéticas diferenciadas tornam as plantas daninhas altamente competitivas pelos recursos do ambiente:água, luz, nutrientes e $\mathrm{CO}_{2}$. Gustafson et al. (2004) afirmam que a elevada velocidade de emergência e de crescimento inicial das plantas daninhas as torna prioritárias na utilização dos recursos do meio e, por isso, geralmente elas levam vantagem na utilização destes.

Nota-se que para o nutriente potássio houve acréscimo no acúmulo em mudas cultivadas juntamente com as plantas daninhas, destacando-se $S$. americanum, com aumento de $86 \%$ (Tabela 4). Perin et al. (2010) afirmam que as espécies capim-de-galinha (Eleusine indica), capim-colchão (Cenhus echinatus), caruru-roxo (Amaranthus hybridus var. paniculatus), caruru-rasteiro (Amaranthus deflexus), picão-preto (Bidens pilosa), botão-deouro (Galinsoga quadriradiata) e tiririca (Cyperus rotundus) podem promover efeitos de ciclagem de potássio similares aos das plantas de cobertura crotalária e milheto. De acordo com Florez et al. (1999) e Rizzardi et al. (2003), baixas densidades de plantas daninhas podem promover efeitos positivos sobre as culturas devido ao efeito complementar entre as espécies, possibilitando algum tipo de interação positiva entre elas sob essa condição; além disso, pode estar envolvida, também, a menor habilidade competitiva de algumas plantas daninhas.

Valores semelhantes aos obtidos pela testemunha (mudas de jatobá - Tabela 4) são relatados por Resende et al. (2000) parajatobá $\left(21,30 \mathrm{~g} \mathrm{~kg}^{-1}\right.$ de N) e Silva et al. (1998) para seringueira $\left(24,16,3,26\right.$ e $33,78 \mathrm{~g} \mathrm{~kg}^{-1}$ de $\mathrm{N}$, P e K).

Considerando o acúmulo de nutrientes pelas plantas daninhas entre os dois modos de cultivo e entre plantas, constata-se para o nitrogênio maior absorção em $S$. americanum quando em cultivo isolado (42\% - Tabela 5). Examinando o fósforo, verifica-se que as espécies que diferiram foram $S$. americanum e L. multiflorum, ambas obtendo, quando em cultivo isolado, maior acúmulo (106 e 51\%, respectivamente).

Tabela 5 - Acúmulo de nitrogênio $(\mathrm{N})$, fósforo $(\mathrm{P})$ e potássio $(\mathrm{K})$ em folhas de plantas daninhas em cultivo solteiro ou em competição com mudas de jatobá

\begin{tabular}{|c|c|c|c|c|c|c|}
\hline \multirow{3}{*}{ Tratamento } & \multicolumn{2}{|c|}{ Nitrogênio } & \multicolumn{2}{|c|}{ Fósforo } & \multicolumn{2}{|c|}{ Potássio } \\
\hline & \multicolumn{6}{|c|}{$\left(\mathrm{g} \mathrm{kg}^{-1}\right)$} \\
\hline & Competição & Isolado & Competição & Isolado & Competição & Isolado \\
\hline Cenchrus echinatus & $19,73 \mathrm{Aa}$ & $23,83 \mathrm{Ab}$ & $8,03 \mathrm{Aa}$ & $10,64 \mathrm{Aa}$ & $36,51 \mathrm{Abc}$ & $22,34 \mathrm{Bb}$ \\
\hline Bidens pilosa & $25,11 \mathrm{Aa}$ & $23,11 \mathrm{Ab}$ & $2,20 \mathrm{Ac}$ & $2,36 \mathrm{Ab}$ & $46,81 \mathrm{Aab}$ & $25,35 \mathrm{Bab}$ \\
\hline Euphorbia heterophylla & $24,89 \mathrm{Aa}$ & $21,63 \mathrm{Ab}$ & $4,58 \mathrm{Aabc}$ & $3,38 \mathrm{Ab}$ & $23,68 \mathrm{Ac}$ & $28,25 \mathrm{Aab}$ \\
\hline Solanum americanum & $29,47 \mathrm{Ba}$ & $41,97 \mathrm{Aa}$ & $3,81 \mathrm{Bbc}$ & $7,85 \mathrm{Aa}$ & $56,04 \mathrm{Aa}$ & $40,90 \mathrm{Ba}$ \\
\hline Lolium multiflorum & $29,45 \mathrm{Aa}$ & $24,86 \mathrm{Ab}$ & $7,40 \mathrm{Bab}$ & $11,19 \mathrm{Aa}$ & $38,35 \mathrm{Abc}$ & $22,55 \mathrm{Bb}$ \\
\hline $\mathrm{CV}(\%)$ & \multicolumn{2}{|c|}{24,62} & \multicolumn{2}{|c|}{31,18} & \multicolumn{2}{|c|}{23,78} \\
\hline
\end{tabular}

Médias seguidas por letras iguais maiúsculas na linha não diferem a $5 \%$ pelo teste $\mathrm{F}$; e as seguidas por letras minúsculas na coluna, para cada variável, não diferem entre si a $5 \%$ pelo teste de Tukey. 
Entre as plantas são notadas consideráveis diferenças, destacando-se C. echinatus e L. multiflorum, com maior acúmulo. Já para o potássio, somente $S$. americanum não diferiu entre os modos de cultivo. Entre plantas, a exemplo do fósforo, também se verificam notáveis diferenças, sendo $S$. americanum a que apresentou maior acúmulo (Tabela 5). A vegetação infestante, que cresce entre as mudas, pode funcionar como reserva de nutrientes que não seriam absorvidos pelas mudas e, por isso, poderiam ser perdidos por lixiviação ou erosão.

Com o crescente interesse no estabelecimento de sistemas silvipastoris e consórcio entre plantas, a avaliação do desenvolvimento de espécies arbóreas na presença de forrageiras e adubos verdes passa a ser importante, e estudos primários sobre competição podem orientar no manejo desses sistemas.

Para os resultados do consórcio entre o jatobá e potenciais espécies consortes, concluise que a competição exercida por essas não compromete as mudas de jatobá em fase inicial de desenvolvimento, mesmo com 60 dias de convivência. O consórcio pode proporcionar redução do teor de nitrogênio e fósforo para a maioria das forrageiras e adubos verdes; contudo, para o potássio, verifica-se incremento no teor.

Quanto ao experimento com plantas daninhas, verifica-se que a convivência com o jatobá promove efeito positivo nelas quanto ao teor de nutrientes aos 60 dias de convivio. É provável que a presença do jatobá promova maior benefício rizosférico, aumentando a interação das infestantes de ciclo rápido com a microbiota edáfica, disponibilizando e/ou influenciando maior quantidade de nutrientes. A avaliação de períodos de interferência superiores a 60 dias pode ser interessante para comprovar a capacidade competitiva do jatobá e evitar a supressão dessa arbórea por espécies consortes ou não cultivadas.

\section{AGRADECIMENTOS}

À Empresa Piraí Sementes, pelo fornecimento das sementes de adubos verdes. Ao Conselho Nacional de Desenvolvimento Científico e Tecnológico (CNPq) e à Fundação de Amparo à Pesquisa do Estado de Minas Gerais (FAPEMIG), pelo suporte financeiro.

\section{LITERATURA CITADA}

ANDRADE, C. M. S.; VALENTIM, J. F.; CARNEIRO, J. C. Árvores de baginha (Stryphynodendron guianense (Aubl.) Benth.) em ecossistemas de pastagens cultivadas na Amazônia Ocidental. R. Bras. Zootec., v. 31, n. 2, p. 574-582, 2002.

BARBIERI JUNIOR, D. et al. Análise de crescimento de Hymenaea courbaril L. sob efeito da inoculação micorrízica e adubação fosfatada. R. Ci. Agro-Amb., v. 5, n. 1, p. 1-15, 2007.

BARROSO, D. G. et al. Diagnóstico de deficiência de macronutrientes em mudas de teca. R. Árvore, v. 29, n. 5, p. $671-679,2005$.

BIANCHI, M. A.; FLECK, N. G.; LAMEGO, F. P. Proporção entre plantas de soja e plantas competidoras e as relações de interferência mútua. Ci Rural, v. 36, n. 5, p. $1380-1387,2006$.

BOCCHESE, R. A. et al. Avaliação da competição entre Brachiaria brizantha cv. Marandu, espécies arbóreas nativas do Cerrado e Eucalyptus citriodora. R. Bras. Bioci., v. 5, S5, p. $153-155,2007$.

CAMPOS, N. R. et al. Características morfogênicas e estruturais da Brachiaria decumbens em sistema silvipastoril e cultivo exclusivo. R. Bras. Bioci., v. 5, p. 819-821, 2007.

CARVALHO FILHO, J. L.S. et al. Produção de mudas de jatobá (Hymenaea corbaril L.) em diferentes ambientes, recipientes e composições de substratos. Cerne, v. 9, n. 1, p. 109-118, 2003.

CARVALHO, L. B.; BIANCO, S.; GUZZO, C. D. Interferência de Euphorbia heterophyla no crescimento e acúmulo de macronutrientes da soja. Planta Daninha, v. 28, n. 1, p. $33-39,2010$

CUI, Q. G.; HE, W. M. Soil biota, but not soil nutrients, facilitate the invasion of Bidens pilosa relative to a native species Saussurea deltoidea. Weed Res., v. 49, p. 201-206, 2009.

DAVIDE, A. C.; BOTELHO, S. A. Análise crítica dos programas de recomposição de matas ciliares em Minas Gerais. In: SIMPÓSIO MATA CILIAR: CIÊNCIA E TECNOLOGIA, Belo Horizonte, 1999. Anais... Lavras: UFLA/FAEPE/CEMIG, 1999. p. 172-188.

DAVIDE, A. C. et al. Restauração de matas ciliares. Inf. Agropec., v. 21, n. 207, p. 65-74, 2000 
DIAS, T. C. S.; ALVES, P. L. C. A.; LEMES, L. N. Períodos de interferência de Commelina benghalensis na cultura do café recém-plantada. Planta Daninha, v. 23, n. 3, p. 397-404, 2005.

DUBOC, E. et al. Nutrição do jatobá. Cerne, v. 2, n. 1, p. 138-152, 1996.

FAVERO, C. et al. Crescimento e acúmulo de nutrientes por plantas espontâneas e por leguminosas utilizadas para adubação verde. R. Bras. Ci. Solo, v. 24, n. 1, p. 171-177, 2000 .

FERNANDES, A. R. et al. Crescimento e absorção de nutrientes por mudas de freijó (Cordia goeldiana HUBER) em função de doses de fósforo e de zinco. R. Árvore, v. 31, n. 4, p. 599-608, 2007.

FERREIRA, O. G. L.; ROSSI, F. D.; ANDRIGHETTO, C. DDA: Software para determinação de área foliar, índice de área foliar e área de olho de lombo - versão 1.2. Santo Augusto: 2008.

FLOREZ, J. A. et al. Predicting rice yield losses caused by multispecies weed competition. Agron. J., v. 91, n. 1, p. 87-92, 1999.

FOWLER, A. J. P.; BIANCHETTI, A. Dormência em sementes florestais. Colombo: Embrapa Florestas, 2000. 27 p. (Embrapa Florestas - Documentos, 40).

GORCHOV, D. L. et al. Dispersal of seeds of Hymenaea courbaril (Fabaceae) in a logged rain forest in the Peruvian Amazonian. Acta Amaz., v. 34, n. 2, p. 251-259, 2004.

GUSTAFSON, D. J.; GIBSON, D. J.; NICKRENT, D. L. Competitive relationships of Andropogon gerardii (Big Bluestem) from remnant and restored native populations and select cultivated varieties. Funct. Ecol., v. 18, n. 3, p. 451-457, 2004.

LORENZI, H. Árvores brasileiras: manual de identificação e cultivo de plantas arbóreas nativas do Brasil. Nova Odessa: Plantarum, 2002. v. 1. 368 p

MALAVOLTA, E; VITTI, G. C.; OLIVEIRA, S. A. Avaliação do estado nutricional das plantas: princípios e aplicações. Piracicaba: POTAFOS, 1997. 319 p.
PERIN, A. et al. Produção de fitomassa, acúmulo de nutrientes e fixação biológica de nitrogênio por adubos verdes em cultivo isolado e consorciado. Pesq. Agropec. Bras., v. 39, n. 1, p. $35-40,2004$

PERIN, A. et al. Acúmulo e liberação de P, K, Ca e Mg em crotalária e milheto solteiros e consorciados. R. Ceres, v. 57, n. 2, p. 274-281, 2010.

PES, L. et al. Comportamento da Erva Mate (Ilex paraguariensis St. Hil.) em consórcio silvicultural. Ci. Flor., v. 5, n. 1, p. 19-32, 1995.

PITELLI, R. A.; KARAM, D. Ecologia das plantas daninhas e sua interferência em culturas florestais. In: SEMINÁRIO SOBRE PLANTAS DANINHAS E O USO DE HERBICIDAS EM FLORESTAMENTO, 1988, Rio de Janeiro. Anais... Rio de Janeiro: ABRACAVE, 1988. p. 1-20. Volume irregular, várias paginações.

PRADO, R. M. Nutrição de plantas. São Paulo: Universidade de São Paulo, 2008. 407 p.

RESENDE, A. V. et al. Acúmulo e eficiência nutricional de macronutrientes por espécies florestais de diferentes grupos sucessionais em resposta à fertilização fosfatada. $\mathbf{C i}$. Agrotec., v. 24, n. 1, p. 160-173, 2000.

RIZZARDI, M. A. et al. Perdas de rendimento de grãos de soja causadas por interferência de picão-preto e guanxuma. Ci. Rural, v. 33, n. 4, p. 621-627, 2003.

SILVA, A. C.; SANTOS, A. R.; PAIVA, A. V. Translocação de nutrientes em folhas de Hevea brasiliensis (clone) e em acículas de Pinus oocarpa. R. Univer. Alfenas, v. 4, n. 1, p. 11-18, 1998.

SILVA, W. et al. Absorção de nutrientes por mudas de duas espécies de eucalipto em resposta a diferentes teores de água no solo e competição com plantas de Brachiaria brizantha. Ci. Agrotec., v. 24, n. 1, p. 147-159, 2000.

SILVA, A. C. et al. Acúmulo de macro e micronutrientes por soja e Brachiaria brizantha emergida em diferentes épocas. Planta Daninha, v. 27, n. 1, p. 49-56, 2009. 